\title{
A MÚSICA SERTANEJA COMO REFLEXO DE TRANSFORMAÇÕES DOS LUGARES DE ESCUTA
}

\author{
Luciana Carolina Fernandes Faria, João Pedro Turino Silva \\ Universidade do Oeste Paulista - UNOESTE, Presidente Prudente, SP. E-mail: luciana.carolina@gmail.com
}

\begin{abstract}
RESUMO
Este artigo tem por objetivo analisar e comparar músicas sertanejas brasileiras, de diferentes décadas, a fim de identificar quais os elementos se conservaram, quais se alteraram com o tempo e as possíveis associações entre estas transformações e o aumento da população urbana. Para isso, foram selecionadas duas músicas sertanejas, uma de 1926 e outra de 2028, a fim de identificar os quais os elementos musicais se transformaram e quais foram conservados com o tempo e sob a influência do processo do êxodo rural. Por pesquisa bibliográfica constatamos que nosso país passou por uma urbanização significativa, principalmente a partir da década de 60 e este fato, agravado pela influência da indústria cultural, causou mudanças de hábitos, ações e, consequentemente provocou alterações nos lugares de escuta das pessoas; as escutas que se faziam e se produziam no ambiente rural se diferem em muitos das escutas que se faz e se produz nos ambientes urbanos hoje. Tais mudanças implicam diretamente na forma de expressão e na produção artística das pessoas. Por pesquisa analítica dos elementos narrativos e musicais essa transformação dos lugares de escuta fica evidente, e demonstra a cultura, as práticas e conceitos de dois contextos sertanejos (rural e urbano) muito diversos. Os lugares de escuta são produzidos pelos seres viventes e, em reciprocidade, também os produz enquanto seres; desta forma, se torna um objeto de investigação importante para a compreensão da sociedade hoje.

Palavras - chave: Lugar de escuta. música sertaneja brasileira. êxodo rural. geografia cultural. geografia humanista.
\end{abstract}

\section{THE BRAZILIAN COUNTRY MUSIC AS A REFLECTION OG CHANGES IN LISTENING PLACE}

\begin{abstract}
This article aims to analyze and compare Brazilian country music from different decades in order to identify which elements have been preserved, which have changed over time and the possible associations between these transformations and the increase in the urban population. For this, two country songs were selected, one from 1926 and the other from 2028, in order to identify which musical elements have been transformed and which have been preserved over the time and under the influence of the rural exodus process. Through bibliographic research, we found that our country has undergone through a significant urbanization, especially since the 1960s and this fact, aggravated by the influence of the cultural industry, caused changes in habits, actions and, consequently, caused changes in people's listening places; the wiretaps that were made and produced in the rural environment differ in many of the wiretaps that are made and produced in urban environments today. Such changes directly imply people's form of expression and artistic production. Through analytical research of the narrative and musical elements, this transformation of the listening places is evident, and demonstrates the culture, practices and concepts of two very diverse contexts (rural and urban). Listening places are produced by living beings and, in reciprocity, also produces them as beings; in this way, it becomes an important research object for the understanding of society today.
\end{abstract}

Keywords: Listening place. Brazilian country music. rural exodus. cultural geography. humanistic geography. 


\section{INTRODUÇÃO}

A música sertaneja é um estilo popular muito difundido e consumido no Brasil; com origem rural, este estilo de música se desenvolveu e se desprendeu este contexto, abrangendo diferentes narrativas, contextos e lugares. Junto a este processo de desenvolvimento e ressignificação é possível acompanhar uma transformação do lugar onde as pessoas habitam e constituem seus ambientes urbanos. É cognoscível, por exemplo, as transformações sociais que ocorreram com o aumento significativo da população urbana; as possibilidades de escutas - seja a partir de ruídos, paisagem sonora ou músicas produzidas pela indústria fonográfica - neste processo também se transformaram.

A partir disso, é possível perceber a música como um indicador das características do grupo social que a produz, constituindo cultura e costumes marcadas por influências espaciais e temporais. Compreender que a música é parte da cultura e indicador das características de um determinado grupo social é uma prática comum e adotada por diversos autores que investigam a sociedade e seu comportamento. Neste artigo buscamos apresentar argumentos que contribuam com esta discussão, explorando, a partir da ideia de "lugar", o conceito de "lugar de escuta", em uma abordagem fenomenológica, a fim de compreender o lugar de escuta como conjunto de ações produzidas pelo ser humano e que, em paridade, o produzem enquanto ser.

A partir de da abordagem fenomenológica, a Geografia Cultural usa dos termos "lugar" e "espaço" para fundamentar a discussão sobre a maneira como determinada sociedade materializa o tempo e a cultura no ambiente em que habita. Yi-Fu Tuan (1983), a partir de uma ótica humanista, apresenta as ideias de "espaço" e de "lugar" com a noção de movimento, ambiente dinâmico, ativo. Distanciando-se do pensamento tradicional da Geografia Naturalista que compreende o espaço como um ambiente pré-determinado, independente do ser que o poderia habitar, Tuan (1983) desperta o interesse pela experiência humana no meio, suas ações e atribuição de significados; desta forma, o autor acrescenta que "lugar" é um termo espacial mais adequado para a Geografia Humanista do que "paisagem", por exemplo.
O conceito de "lugar" é definido de inúmeras formas dentro dos mais diversos segmentos da geografia, todavia escolhemos nos debruçar na perspectiva da geografia humanista de lugar, em que Tuan (1983) define-o da seguinte forma: "O lugar é um mundo de significados organizado".

Logo, o "espaço" que, segundo Tuan (1983), daria certa ideia de, se contrapõe ao "lugar" que seria um "espaço" de significados, ou em outro momento, um mundo de significados organizado, ou seja, o lugar carrega em si afetividade.

O espaço é um símbolo comum de liberdade no mundo ocidental. 0 espaço permanece aberto; sugere futuro e convida à ação. [...] 0 espaço aberto não tem caminhos trilhados nem sinalizações. Não tem padrões estabelecidos que revelem algo, é como uma folha em branco na qual se pode imprimir qualquer significado. $O$ espaço fechado e humanizado é lugar. Comparado com o espaço, o lugar é um centro calmo de valores estabelecidos (TUAN, 1983, p. 61).

Destacamos, então, como esta noção de lugar se diferencia da compreensão tradicional de espaço. Compreender o espaço como "uma folha em branco", sem "caminhos trilhados nem sinalizações" faz desse espaço uma representação de lugar, algo separado da vida mesma, distante da percepção e ação humana. Há, então, uma lógica de inversão, em trocar o fenômeno próprio da vida pela sua representação, ou ideal, controlável, quantificável e livre da subjetividade humana.

A inversão transforma as vias ao longo das quais a vida é vivida em limites dentro dos quais está encerrada. A vida, de acordo com esta lógica, é reduzida a uma propriedade interna de coisas que ocupam o mundo, mas, estritamente falando, não o habitam. 
Um mundo que seja ocupado, mas não habitado, que está cheio de coisas existentes, em vez de tecido a partir dos fios do seu devir, é um mundo de espaços (INGOLD, 2015, p. 215).

Notamos que há na cultura Ocidental e na Ciência Moderna essa tendência em trocar a experiência de mundo pela representação nas mais diversas áreas; seja no método científico que posiciona o pesquisador como um observador do mundo, não participante do fenômeno, seja na ciência cognitiva clássica que coloca o ser humano como um "percebedor" passivo de um mundo pré-determinado e independente de sua ação. A partir da fenomenologia passamos a considerar que os significados não estão nos objetos que ocupam espaços, mas está no acoplamento e na ação mútua entre o meio e o ser vivo que o habita.

Já no conceito de "lugar" há o apreço pela história das relações humanas vividas; não se refere a um espaço geográfico qualquer, mas a um espaço específico, marcado por ações sociais específicas, de povos de culturas específicas, em tempos determinados.

Lugares seria, portanto, pontos de encontro de redes de relações sociais, movimentos $\mathrm{e}$ comunicações cujas relações recíprocas tenham sido construídas em escala muito maior do que aquelas definidas para o lugar naquele momento. Estas relações como sistema amplo não são apenas ritualísticas, mas relações reais com conteúdo econômicos, políticos e culturais reais (FERREIRA, 2000, p. 75).

Por este viés, lugar é definido por valores que vão além das características geográficas como densidade demográfica, solo, clima, relevo, hidrografia, entre outros; mas é marcado por elementos subjetivos, vínculos afetivos, história de ações dos seres que o habitam. Este vínculo que faz o lugar - e igualmente faz o ser - gera o sentimento de pertencimento.
Ao invés de pensar em nós mesmos apenas como observadores, trilhando nosso caminho ao redor dos objetos espalhados pelo chão de um mundo já formado, devemos imaginar-nos, em primeiro lugar, como participantes, cada um imerso com todo nosso ser nas correntes de um mundo em formação: na luz solar nós vemos, a chuva na qual ouvimos e o vento no qual sentimos. Participação não se opõe a observação, mas é uma condição para isso, assim como a luz é uma condição para se ver as coisas, o som para ouvi-las e a sensação para senti-las (INGOLD, 2015, p. 197).

No caso da escuta, a significação não está pronta no som, enquanto entidade, a significação está na ação e no acoplamento do ser com o meio; de forma que é possível afirmar que não escutamos o som, mas escutamos no som. As escutas que fazemos em nossos lugares, resultado da nossa ação naquele lugar, constitui nossa própria história, nossa personalidade.

Partindo desse entendimento, o lugar onde estamos, é onde atribuímos sentido aos fenômenos, o ambiente já não é mais apenas físico tem sua importância e um pouco de nós, enquanto nós temos um pouco do lugar.

Sendo o lugar um ambiente no qual há um afeto estabelecido, sentimento, subjetividades, sentido de pertencimento e necessidade da ação do ser que o habita, há de se convir que, de acordo com seu lugar, o ouvinte produz e reproduz escutas específicas. Em sua tese de doutorado, Faria (2019) corrobora ao afirmar que o "Lugar de Escuta" contempla a ideia da experiência (subjetiva) que se tem através da percepção da música, ou seja, a escuta como resultado da realidade de cada um, sua vida, seu lugar e sua história.

Para Faria (2019, p. 58) "Lugar de escuta não é apenas um espaço de possibilidades de escutas, mas é um lugar que faz o ser e que é feito por ele". Mais do que uma "paisagem sonora", com sons que ocupam espaços, o conceito de lugar de escuta posiciona o ser como 
aquele que age no meio produzindo escutas e se produzindo por elas.

A partir desta fundamentação, direcionamos nossa investigação para a música sertaneja, apreciando transformações profundas em suas características musicais e narrativa ao logo dos anos. Nos dias de hoje reconhecemos uma música sertaneja universitária, diferente das mais antigas, certamente porque a realidade dos novos compositores, e também dos ouvintes, é bem diferente do contexto da música sertaneja dos últimos 50 anos. Nosso país passou por uma urbanização significativa, principalmente a partir da década de 60; atualmente, a maioria esmagadora de nossa população é urbana.

Ainda nessa reflexão, aqueles que escutam convivem com situações diferentes e se distanciaram intensamente $\mathrm{da}$ realidade do campo; o "lugar de escuta" se alterou para muitos e a música expressa hoje uma mensagem menos ligada ao cotidiano rural e mais com canções românticas, sobre festas e outros programas relacionados à vida urbana. Enquanto as gerações mais próximas ao sertanejo universitário são conformadas com o mesmo, as gerações mais antigas podem se sentir não mais pertencentes a essa experiência que não contempla mais "lugar de escuta" dos que tiveram como lugar o ambiente rural.

Logo, a música feita e ouvida sendo resultado e consequência dos lugares onde estamos diz muito sobre quem somos e onde estamos; é diante dessa afirmação, que nos interessamos pelos novos lugares de escuta no Brasil, e pela nova música sertaneja. Seria o sertanejo de hoje consequência dos novos lugares de escuta? Acreditamos que sim, ainda que não apenas por isso, a presença de elementos muito mais urbanos nas canções sertanejas atuais, os valores, os temas das canções e as roupas usadas já não contemplam os lugares de escuta dos mais antigos "caipiras".

Destarte, o objetivo deste trabalho é analisar e comparar músicas sertanejas brasileiras, de diferentes décadas, a fim de identificar quais os elementos se conservaram, quais se alteraram com o tempo, e as possíveis associações entre estas transformações e o aumento da população urbana.

\section{MÉTODOS}

Para isso, selecionamos duas músicas sertanejas de períodos diferentes: "Tristeza do Jeca" de Angelino de Oliveira (melodia composta em 1918 e letra em 1926), e "Posto 24h" de Jujuba, Bruninho Moral, Hiago Nobre e Xuxinha, (composta e gravada em 2018), afim de identificar elementos, tanto na narrativa como na melodia e arranjo musical, que evidencie os diferentes lugares de escuta dos "sertanejos" que interpretam e escutam estas músicas.

Foram analisadas as letras das músicas, identificando descrições dos lugares da narrativa, além dos elementos musicais como instrumentação, timbres, formas musicais, andamento e caráter musical, ritmo, harmonia, melodia, entre outros. Configurando, assim, uma análise qualitativa de conteúdo, seguindo estas categorias de análise.

\section{RESULTADOS}

Apresentamos, então, as duas músicas selecionadas como objeto de estudo; uma, de 2018, gravada por um sertanejo contemporâneo com elementos da música Pop já consolidados pela indústria fonográfica, e outra que surgiu apenas como canção instrumental nas primeiras décadas do século $X X$, e se tornou um clássico do sertanejo, performada por inúmeros cantores. Segue a transcrição da música, pelos autores.

Nestes verso tão singelo, minha bela, meu amor / Pra você quero contar o meu sofrer e a minha dor / Eu sou que nem o sabiá quando canta é só tristeza desde o gaio onde ele está / Nesta viola eu canto e gemo de verdade, cada toada representa uma saudade

Eu nasci naquela serra num ranchinho beira chão / Tudo cheio de buraco d'onde a Lua faz clarão / Quando chega a madrugada lá no mato a passarada principia um baruião

Nesta viola eu canto e gemo de verdade, cada toada representa uma saudade / Vou parar com a minha viola já não posso mai cantar / Pois o Jeca quando canta tem vontade de chorar / 0 choro que vai caindo, devagar vai se sumindo, como as água vão pro mar / Nesta viola eu canto e 
gemo de verdade, cada toada representa uma saudade.

Notamos nesta canção que sua letra apresenta diversos elementos integram a vida no campo; o sabiá, serra, o ranchinho beira chão, a passarada no mato que canta quando chega a madrugada, a metáfora do choro que cai como as águas correm pro mar, todas estas são expressões e escutas comuns em lugares rurais, habitados por pessoas que dedicam suas vidas aos trabalhos rurais, próximo a natureza, e encontram na canção, uma forma de expressar seus sentimentos, saudade e tristeza. A canção tem um caráter melancólico, de um caipira que lamenta a saudade de sua "bela". É marcante, também, a linguagem coloquial, própria da cultura caipira.

Quanto aos elementos musicais, notamos que os instrumentos são a viola, o violão e as vozes em dueto. A instrumentação e o arranjo musical simples, sem grandes evoluções e modulações, evidenciam a atenção dada à narrativa, à história que se conta. As vozes apresentam timbres abertos e brilhantes, a canção é cantada de forma melancólica, mas com energia, com volume de voz firme. A forma musical é estrófica, com um pequeno refrão, que, não tendo grande destaque no arranjo, se mistura à sequência narrativa. Sua composição harmônica abrange as funções tonais principais, como tônica, subdominante e dominante, mas se usa de apenas três acordes. A melodia principal da música se contrapõe a pequenos ponteios da viola que complementam os intervalos do canto.

Em outro contexto, apreciamos a segunda canção selecionada neste trabalho, com transcrição dos autores.

O tira gosto esfriou, a cerveja esquentou / $\mathrm{O}$ cigarro queimou a ponta do meu dedo / Essa festa acabou, meus amigo vazou / E a dona do bar 'tá fechando mais cedo / $\mathrm{E}$ aonde é que meu coração fica nessa hora? / Qualquer homem durão nesse momento chora / Sem ela na minha casa eu não me sinto bem / Eu sem amor e sem bebida sou um Zé ninguém / E o posto 24 horas é o point dos largados / Olha eu virado bebendo por ela e o povo abastecendo indo pro trabalho / E aonde é que meu coração fica nessa hora / Qualquer homem durão nesse momento chora / Sem ela na minha casa eu não me sinto bem / Eu sem amor e sem bebida / E o posto 24 horas é o point dos largados / Olha eu virado bebendo por ela e o povo abastecendo indo pro trabalho.

A segunda canção em questão, traz um outro lugar, com elementos urbanos e o próprio assunto tratado se dá em um posto de gasolina 24 horas, que tem uma conveniência e serve de refúgio aos "largados". A bebida como refúgio diante de uma decepção amorosa não é tema recente no sertanejo, porém, é sim um dos temas mais retratados nas canções atuais. Enquanto a narrativa da música Tristeza do Jeca busca a viola, a toada e a canção como forma de expressar sua tristeza e sua saudade, na música "Posto $24 \mathrm{~h}$ " esse sentimento de tristeza e saudade é expresso pelo consumo da bebida e cigarro, em um ambiente que não é o doméstico. As expressões "O povo abastecendo e indo pro trabalho", "essa festa acabou" e "posto 24 horas" são elementos da cidade, do cotidiano da mesma.

Vale pontuar que, como também identificamos na música Tristeza do Jeca, as gírias e a linguagem coloquial sempre estiveram presentes e são elemento característico da música sertaneja, porém, nesta mais atual, notamos duas diferenças relevantes; a pronuncia do " $r$ " já não é tão forte como na música e na fala caipira rural, e, além disso, as gírias caipiras foram substituídas por expressões como "point", "vazou", "virado", "Zé ninguém" e verbos não conjugados.

Na gravação desta segunda música, notase a presença de muitos instrumentos como guitarras, violões, baixo, bateria, gaitas ou sanfonas, instrumentos de sopro como saxofone, trompete e trombone. As vozes, apesar de se organizarem em dois cantores mais backing vocal, não se configura em dueto como na música sertaneja antiga; marca da cultura pop e da tentativa da indústria cultural em dissociar esta música da imagem caipira. 
O arranjo é constituído de diversos pontos de evolução, começando a primeira parte da música com introdução instrumental, a primeira estrofe com acompanhamento harmônico e rítmico simples e mais "vazio", enquanto que, no refrão outros instrumentos participam causando um crescente no padrão de acompanhamento rítmico, melódico e harmônico. A harmonia desta canção apresenta as três funções tonais principais, mas faz uso de diversos acordes do campo harmônico e não apenas os três principais. O ritmo, tanto da bateria com a rítmica da melodia dos instrumentos de sopro, explora constantemente os contratempos do compasso, com acentuações e convenções próprias da levada do sertanejo universitário; bem contrastante com o ritmo padrão e contínuo da música sertaneja antiga.

Quanto a forma musical, percebemos nesta mais atual uma narrativa mais curta e com incidência de repetições mais constantes; diferente da "Tristeza do Jeca" em que o refrão é cantado quase que no contínuo da música, no "Posto $24 \mathrm{~h}$ " o refrão é destacado no arranjo e repetido muitas vezes. Podemos argumentar que, em razão deste esquema estrutural da música, a ênfase na narrativa é muito menor, dando destaque à instrumentação e ao ritmo dançante.

\section{DISCUSSÃO}

Antes de tudo precisamos antes compreender o estilo musical e, para isso, buscamos em Zan (2016) que apresenta um resgate sobre a música caipira; ele nos revela que o modo de vida representado nas matrizes do sertanejo de hoje praticamente desapareceu. A cultura caipira estava ligada a um modo de vida baseado na pequena produção de subsistência, em que os sítios formavam unidades sociais caracterizadas por relações de parentesco e de legalidade vicinal. Estavam localizados em lugares bem específicos: Estado de São Paulo, sul de Minas gerais, Sul de Goiás, sudeste do mato grosso do Sul e Norte do Paraná. As canções contavam longas histórias e eram sempre tocadas em encontros à beira da fogueira, em um café após um dia de trabalho ou outra refeição. Vale salientar, também, que esse universo abrange uma religiosidade onde havia festivas quermesses, um elemento essencial nesse universo cultural.

O autor supracitado apresenta a evolução da música sertaneja em mais duas fases, o "sertanejo pop" e o "pós caipira". O "sertanejo pop" seria o sertanejo que surge na década de 60 , presente nos programas de televisão e influenciados pela cultura norte americana; a figura dos interpretes já não vestem mais roupas velhas nem são mais banguelas, são agora famosos e bem vestidos, com músicas fazendo sucesso nas rádios e contratos com gravadora. Ademais, devemos considerar a situação do país neste mesmo período da década de 60 , momento em que o Brasil começava a se industrializar e os interesses econômicos na cultura e na música começam a se organizar e consolidar.

Caldas (2005, p. 65) nos auxilia na compreensão deste período e dos anos seguintes ao afirmar que "A imagem do cowboy americano substituirá, no cancioneiro sertanejo, a figura solitária e desolada do caipira brasileiro". E, de fato, a figura do "cowboy" tão presente nos filmes de "bang bang", em evidência na cultura dessa época, passa a ser a figura inspiradora para as novas vestimentas, valores e até a musicalidade, o sertanejo começa a inserir a música country em si.

Para Zan (2016), o "pós caipira" parece ter absorvido por completo elementos do rock e do pop, de forma que a partir da década de 90 surgiram as novas duplas sertanejas, configuradas em imagens muito mais urbanizadas, com música sobre romance e as vivências na cidade; duplas que criam verdadeiros "hits", e se utilizam de instrumentos e tecnologias jamais sonhados pelos primeiros caipiras.

É possível constatar que as duplas sertanejas que surgiram a partir dos anos 2000 têm agregado à sua música cada vez mais novidades como elementos da música eletrônica e influências da música latina.

Faustino (2007) compreende a música caipira, desde a década de 70 , como um estilo musical que usa de mediações, para passar alguma mensagem; usava de temas mais abrangentes e populares, como romances, traições e o cotidiano como estratégia para que todos ouvissem, e dessa forma, eram expostas suas ideias e críticas, de forma subliminar, intrínsecas a esses temas. Assim, vemos que a estratégia de inserção da música sertaneja não é atual, mas sempre apresentou meios para isso, e algo além dessas mediações é a capacidade do sertanejo de se associar a outros estilos musicais, e dialogar com várias influências.

Diante do exposto sobre o que é a música sertaneja, entramos em uma discussão em que 
buscamos compreender a relação entre o êxodo rural e a música sertaneja. Argumentamos que este processo de mudança da vida rural para a vida urbana produz novos hábitos, novas ações e, consequentemente novos lugares de escuta.

Analisando o aumento da população urbana podemos perceber que, em 1965, esta tornou-se maior que a rural, e, a partir disso, houve aumento da desigualdade populacional entre a realidade urbana e rural; em 2010 a população morando nas cidades corresponde a mais de 150 mil habitantes, enquanto o campo brasileiro representa menos de 50 mil.

Percebemos que a música caipira, que abordava sobre sua realidade rural refletia, por mais de duas décadas (50 e 60), a realidade de pelo menos metade da população do Brasil. Contudo, a partir da década de 60, principalmente, a música sertaneja passa a expressão e escuta de outras realidades e certamente, também composta por novas realidades. De fato, a música é um indicador da realidade da sociedade que a cria, e a sociedade é cheia de costumes e culturas carregadas de influencias espaciais e históricas, os que saíram do campo trouxeram consigo as canções caipiras para a cidade, e as gerações seguintes tiveram contato com essas canções de alguma forma; logo, as referências de música sertaneja ainda presentes no contexto urbano, foram se reinventando ao longo das décadas de urbanização do Brasil.

Para que a música sertaneja atingisse esse novo público, ela se alterou de forma que fizesse mais sentido aos novos lugares de escuta. O cotidiano da "roça" e os "causos" são substituídos por canções de amor, decepções amorosas e cotidiano da vida na cidade. Ainda nesse sentido, aqueles que escutam convivem com situações diferentes e se distanciaram intensamente da realidade do campo; o "lugar de escuta" se alterou para muitos e a música com uma mensagem menos ligada ao cotidiano rural e mais com canções românticas, sobre festas e outros programas relacionados a vida urbana.

Outro fator influente nesta transformação da música sertaneja, sem dúvida é a indústria cultural, cultura de massa, que busca estabelecer padrões a partir do consumo para o reestimular ainda mais. Assim, a criação da obra de arte será sempre submetida às regras da indústria, de forma que os compositores, ao produzir a música enquanto mercadoria, precisam atender as "demandas do mercado".
A constatação chega a ser cruel: no capitalismo, apenas não se paga para respirar! $\mathrm{E}$ a própria música inexoravelmente submeter-se-á, aí, à sua condição de mercadoria: quanto mais elaborada, menos procurada. [...] No caso específico das elaborações musicais mais consequentes, a relação entre criação e seu consumo passa irrevogavelmente pela dialética entre concepções musicais e sua legitimação como necessidade social, ou seja, pela relação obra musical/ouvinte

(ADORNO, 2011, p 16-17).

Uma observação ingênua das músicas sertanejas universitárias pode nos despertar a atenção para a semelhança estrutural, rítmica, melódica e harmônica das músicas desse estilo; de forma que quando um produto musical atinge grande nível de consumo, é tido como padrão para a reprodução de outros produtos iguais. Assim, muitas músicas sertanejas hoje compartilham da mesma sequência harmônica, melodias tão semelhantes que aparentam até plágio, entre outros elementos.

Enquanto as gerações mais próximas ao sertanejo universitário são conformadas com o mesmo, as gerações mais antigas podem se sentir não mais pertencentes a essa sonoridade que não contempla mais o lugar de escuta dos que têm como lugar o ambiente rural.

\section{CONCLUSÃO}

Os lugares de escuta são produzidos pelos seres viventes e, em reciprocidade, também os produz enquanto seres; desta forma, se torna um objeto de investigação importante para a compreensão da sociedade hoje. Este assunto, sob o viés da fenomenologia, ainda é recente, tanto na área da Geografia quando na Música, de forma que o conceito de lugar de escuta está em processo de construção. Destarte, nosso objetivo não é esgotar este assunto, mas fomentar a discussão e a produção científica, ainda escassa, a fim de compreender a quais escutas estamos submetidos, quais escutas produzimos em nossa sociedade e como esta 
ação impacta em nossas vidas e nosso processo de desenvolvimento humano.

\section{AGRADECIMENTOS}

Os autores declaram não haver qualquer potencial conflito de interesse que possa interferir na imparcialidade deste trabalho científico.

\section{REFERÊNCIAS}

ADORNO, T. W. Introdução à sociologia da música: doze preleções teóricas. São Paulo: Editora Unesp, 2011.

CALDAS, W. Revendo a música sertaneja. Revista USP, n. 64, p. 58-67, 1 fev. 2005. https://doi.org/10.11606/issn.2316-

9036.v0i64p58-67

FARIA, L. C. F. O jogo eletrônico como lugar de escuta. 2019. 123 f. Tese (Doutorado em Tecnologias da Inteligência e Design Digital) Pontifícia Universidade Católica, São Paulo, 2019.

FAUSTINO, J. C. Rosinha e Catimbau: análise de um processo de transformação social através da música caipira. História Social, n. 13, p. 221-239, 11, 2007.

FERREIRA, L. F. Acepção recentes do conceito de lugar e sua importância para o mundo contemporâneo. Revista Território, Rio de Janeiro, ano 5, n. 9, p. 65- 83, jul./dez., 2000.

INGOLD, T. Estar vivo: ensaios sobre movimento, conhecimento e descrição. Petrópolis, RJ: Vozes, 2015.

TUAN, Y. F. Espaço e lugar: a perspectiva da experiência. São Paulo: Difel, 1983.

ZAN, J. R. (Des)Territorialização e Novos Hibridismos na Música Sertaneja. Sonora, v. 1, n. 2, 2016. 